\title{
David H. Koch Institute for Integrative Cancer Research at MIT
}

National Cancer Institute

\section{Source}

National Cancer Institute. David H. Koch Institute for Integrative Cancer Research at

MIT. NCI Thesaurus. Code C39350.

David H. Koch Institute for Integrative Cancer Research at MIT is committed to shortening the time needed for breakthrough discoveries to directly benefit cancer patients. The Institute builds on the Center's tradition of scientific excellence and promotes the development of innovative ways to diagnose, monitor, and treat cancer through advanced technology. It became an NCl-designated cancer center in 1974 . 